\title{
The Relationship between Legal Systems and Economic Development: Integrating Economic and Cultural Approaches
}

\begin{abstract}
Amanda J. Perry*
This paper seeks to demonstrate the need to bridge the gap between the economic and culture-based approaches to two issues which are fundamental to the debate over the relationship between legal reform and economic development: (a) the relative importance which economic actors around the world place on the legal system and (b) the core components of an effective legal system, as defined by those economic actors. It first outlines the major tenets of current economic legal reform policy, focusing on its underlying assumption that the perceptions and expectations of economic actors around the world do not vary significantly. Data from Geert Hofstede's study of variance in cultural values are then analysed in order to demonstrate how cultural values might affect private sector perceptions and expectations of legal systems as supporters of material progress. It concludes that there is a clear need for a more interdisciplinary approach to the debate over the relationship between legal reform and economic development, and the potential variance in private sector perceptions and expectations of legal systems in particular. Such an approach might be initiated through a systematic integration of existing data and theory from each discipline, reinforced by a new multi-country survey.
\end{abstract}

\section{INTRODUCTION}

International development organizations and commentators generally agree that a central function of the state is to create and enforce rules which support economic growth, and all major multilateral and bilateral

* Department of Law, Queen Mary, University of London, Mile End Road, London E1 4NS, England

Many thanks to Roger Cotterrell, Julio Faundez, Tom Ginsburg, Geert Hofstede, Niels Noorderhaven, Chris Perry, and Sol Picciotto for comments on earlier drafts of this article. 
development organizations have been promoting legislative and institutional reform (hereinafter 'legal reform') in developing and transition economies since the 1980s. ${ }^{1}$ An important feature of contemporary legal reform has been a heavy influence of economic tools of analysis and value systems, and a resulting failure to take account of the literature and lessons of other disciplines (such as law and anthropology, law and sociology, and culture studies generally). This paper seeks to demonstrate the need to bridge the gap between the economic and culture-based approaches to two issues which are fundamental to the debate over the relationship between legal reform and economic development:

(a) the relative importance which economic actors around the world place on the legal system and

(b) the core components of an effective legal system, as defined by those economic actors.

The paper begins by outlining the major tenets of current economic legal reform policy, which is grounded in an emphasis on private-sector-led development. It is assumed, both for the sake of argument and in deference to economics as a well-established discipline, that this emphasis is economically justifiable. Next, the paper focuses on the underlying assumption of current legal reform policy, manifested in the promotion of a uniform market-allocative rule-based model for legal reform, that the perceptions and expectations of economic actors around the world do not vary significantly. Finally, this assumption is challenged using Geert Hofstede's study of variance in cultural values. ${ }^{2}$ His findings are analysed in order to demonstrate how cultural values might affect private sector perceptions and expectations of legal systems as supporters of material progress.

It is concluded that there is a clear need for a more interdisciplinary approach to the debate over the relationship between legal reform and economic development, and the potential variance in private sector perceptions and expectations of legal systems in particular. Such an approach might be initiated through a systematic integration of existing data and theory from each discipline, reinforced by a new multi-country survey.

1 Past and present legal reform strategies have been extensively documented elsewhere. Useful overviews of theory and practice can be found in B. Tamanaha 'Review Article: The Lessons of Law and Development Studies' (1995) 89 Am. J. of International Law 470 and T. Ginsburg 'Does Law Matter for Economic Development? Evidence from East Asia' (2000) 34 Law and Society Rev. 829.

2 G. Hofstede, Cultures and Organizations: Software of the Mind, Intercultural Cooperation and its Importance for Survival (1997). See, also, the first edition of the original study: Culture's Consequences: International Differences in Work-Related Values (1980) and the updated second edition (2001) which emerged too late to be included in this piece. 
Modern legal reform programmes have been influenced by two factors which are of importance to this paper. First, there is a broad consensus that the public sector should be guided by the needs and values of the private sector. Law reform programmes have increasingly been touted as 'the elixir for the developmental needs of a supposedly post-ideological and more pragmatic world', in which the liberal economic paradigm was the only remaining hope for development. ${ }^{3}$ What appears to have been forgotten is that a vast array of cultural ideologies have survived the death of communism, and that those ideologies play a significant role in determining what is 'pragmatic' at any given time.

Second, legal reform has been dominated by development organizations, which are in turn dominated by economists. As a result, legal reform appears to have suffered from two features which some leading insiders consider to be characteristic of modern economics: a lack of interdisciplinarity and a lack of realism. For example, in an essay entitled Disregard of Reality, Peter Bauer bemoans the cycle of isolation and specialization in economics. He remarks that: ${ }^{4}$

Economists systematically exaggerate the impact of their ideas ... Keynes insisted that in the long run the world is governed by little else than the ideas of economists and political philosophers. If this were true, the world would have enjoyed the benefits of free trade for at least one-hundred years. Apart from being obviously unsustainable, Keynes's opinion is also naively parochial in attributing exclusive influence to the ideas of economists and political philosophers. He neglects the impact of founders and leaders of religious movements, including the Buddha, Christ, Mohammed, and of military commanders such as Alexander the Great, Julius Caesar, and Napoleon.

In The Firm, the Market and the Law, Ronald Coase is similarly frustrated by the preference of most economists for the fanciful world of 'blackboard economics' that is, the kind of economics in which 'all the information needed is assumed to be available and the teacher plays all the parts'. Economists are certainly not unique in this regard, but this does not excuse the fact that such an approach 'misdirects our attention' towards unrealistic theory, and away from considering the real relationship between legal systems and economic actors. ${ }^{5}$

3 L. Tshuma 'The Political Economy of the World Bank's Legal Framework for Economic Development' (1999) 8 Social and Legal Studies 75, at 79.

4 P. Bauer, From Subsistence to Exchange and other Essays (2000) at 15.

5 R. Coase, The Firm, the Market and the Law (1988) at 1, 8-10, 13-20, and 158. Bauer, id., at p. 21, makes a similar point when he attacks the increasing mathematization of economics: 'What we see is an inversion of the familiar Hans Anderson story of the Emperor's New Clothes. Here there are new clothes, and at times they are haute couture. But all too often there is no emperor within'. 
Economics has made significant forays into (or returns to) realism. For example, a recent study by economist Paul Ormerod explains that traditional economics is broadly unable and unwilling to cope with complex social or cultural issues, because the entire discipline is based on the assumption that choices made by one individual are never affected by the choices of others. He demonstrates time and again that this assumption is patently untrue, and proposes a new framework for the study of choice 'Butterfly Economics' - based on the deceptively simple principle that individual choices are in fact made on the basis of past choices, of new information, or of the choices of other economic actors. ${ }^{6}$ However, such innovation is rare, and it is more common to find contemporary examples of economic isolationism and fantasy. In the context of legal reform, some significant progress has recently been made in developing methods for the measurement of differences between legal systems. ${ }^{7}$ But little attention has been paid to the objective documentation of differences in privatesector attitudes to those legal systems. Such a lapse is all the more striking in light of the current emphasis on private-sector-led development. In particular, development organizations have failed to examine directly the rather obvious issue of how cultural values might affect private sector perceptions and expectations of legal systems around the world. This appears to be the result of the blackboard-based, econo-centric assumption that all individuals are motivated in the same way and by the same, strictly economic, factors.

The appeal of this approach is perhaps reinforced by two features specific to modern development assistance. First, development organizations are often politically and legally restricted to considering and advising upon economic rather than political matters. ${ }^{8}$ They have therefore sought, with variable success, to focus upon the processes which governments use to govern economic activity and their capacity to implement those processes, and to avoid discussion of the political structure within which governments operate. ${ }^{9}$ Issues such as 'culture' thus fall neatly by the wayside. Second, development organizations are increasingly less able to cope with the debate over who bears responsibility for the limited material progress of developing countries developing countries themselves or their richer neighbours. That debate is complicated, deeply emotive and, mercifully, beyond the scope of this

6 See, generally, P. Ormerod, Butterfly Economics (2000). Butterfly Economics is particularly useful for predicting and explaining phenomena such as stock market booms or crashes and the failure or success of a movie, which appear to be at once random (unpredictable) and systematic (resulting from strong trends in decision making).

7 See, for example, the work of the World Bank Institute at <www.worldbank.org/ $\mathrm{WBI} /$ governance>.

8 World Bank Articles of Agreement, Article III, Section 5(b).

9 Tshuma, op. cit., n. 3, pp. 78-81. 
paper. ${ }^{10}$ However, it is vital to observe that at the same time as development organizations have placed increasing emphasis on the role of internal policies and procedures in economic development, international political opinion has made it progressively more dangerous to be seen to be 'blaming' developing countries in any way for their plight. ${ }^{11}$ As a consequence of these two factors, politics and culture have at once been relocated to explicit no man's land and implicit centre stage.

Material progress 'depends on personal qualities, social institutions and mores, and political arrangements which make for endeavour and achievement' ${ }^{12}$ What development organizations seem powerless to confront is how those personal qualities, social institutions and mores, and political arrangements upon which material progress is dependant might vary, with successful results.

\section{Discretion and the market-allocative rule-based model}

That economists hold sway over legal reform is evident in the terminology used by development organizations to classify legal systems. A range of classifications have been developed for analysing legal systems in the fields of comparative law, law and anthropology, and law and sociology. A 1998 study by the Asian Development Bank (ADB) provides a useful method for the classification of legal systems for the purposes of this paper. ${ }^{13}$ This use of the ADB system should not be taken as a value judgement. Rather, it is chosen in order to demonstrate dominant legal reform policy's underlying emphasis on private-sector-led development, and its emphasis on economic tools and values.

The study proposes classification along the two 'continuous' dimensions. The 'allocative dimension ... refers to legal rules that stipulate who determines the allocation of economic resources in society'. Allocation by the state is at one end of the spectrum, and allocation by the market is at the other. ${ }^{14}$

10 As Bauer (op. cit., n. 4, pp. 60, 71 and 76) explains, a perverse result of refusing to blame developing countries is that development organizations tend to promote an 'image of the Third World as a uniform stagnant mass devoid of distinctive character' and to 'imply that Third World people do not know what is good for them nor even what they want'. In fact, 'people often refuse to abandon attitudes and mores which obstruct economic performance. They are not prepared to give up their established ways for the sake of greater prosperity'. Importantly, this 'is a preference which is neither unjustified nor reprehensible'.

11 id., pp. 53-72.

12 id., p. 76.

13 K. Pistor and P. Wellons, The Role of Law and Legal Institutions in Asian Economic Development 1960-1995 (1998).

14 id., pp. 27 and 50. The rule-based legal system bears obvious similarities to the 'logically, formally rational' legal system identified by Weber and explained in D. Trubek, 'Weber on Law and Capitalism' (1972) 3 Wisconsin Law Rev. 720, at 720. 
The 'procedural' dimension 'captures how law is to be promulgated and enforced as well as the functioning of legal and administrative institutions that support the enforcement of law'. These functions may be 'rule-based' or 'discretionary'. In 'rule-based' legal systems, 'state action is bound by law'; second, 'to be valid, pre-established legal procedures about rule making and rule enforcement have to be complied with'; and third, 'in cases where these principles are violated, non-state actors have recourse to legal review'. By contrast, in 'discretionary' legal systems state agents are able to set and enforce rules 'without significant constraints'. ${ }^{15}$

The ADB study concludes that legal systems in Asia and the West have begun to converge in the thirty-five years since high-speed growth in Asia began. Economic laws have generally moved from a 'state-allocative model', in which the state is responsible for determining the allocation of economic resources; to a 'market-allocative model', in which that function is increasingly played by the market. At the same time, legal institutions in the two regions have generally moved from creating and implementing laws in a 'discretionary' fashion, towards a more 'rule-based' approach. However, the move is far from complete. Substantial differences remain, both among the legal institutions of Asian countries, and between the legal institutions of Asian and Western countries. Importantly, Asian legal systems retain significant state-based and discretionary elements. ${ }^{16}$

The ADB study does not address the question of whether all legal systems will or should eventually harmonize towards the market-allocative rulebased model, but contemporary prescriptions for legal reform do fall squarely into the market-allocative rule-based quadrant of the ADB typology. This paper seeks to demonstrate that these prescriptions are not entirely convincing, because they have been devised without any reference to whether variations in cultural values might result in corresponding variations in private sector perceptions and expectations of legal systems.

Central to the Washington Consensus is that certainty (or predictability) is a key component of any legal system which is to justly and effectively support economic activity. It is argued that certainty is only truly achieved through adherence to the 'rule of law', ${ }^{17}$ that is, by limiting the discretionary powers of the state and individual bureaucrats, and replacing such discretion with the transparent and consistent application of rules created by systematic procedures. In the eyes of the Washington Consensus, discretion is associated with old-school state-centric development plans; and connotes excessive and arbitrary interference by the state in those economic functions in which the market has a competitive advantage and which are therefore

15 Pistor and Wellons, op. cit., n. 13, p. 27.

16 id., pp 27, 263, and 289.

17 For a detailed examination of the concept of the rule of law, see D. Campbell, 'What is Meant by "the Rule of Law" in Asian Company Law Reform?' in Company Law in East Asia, ed. R. Tomasic (1999) 11-38. 
outside of the proper jurisdiction of the state. ${ }^{18}$ In accordance with the teachings of public choice theory, bureaucrats are viewed as essentially 'selfserving and rent-seeking', and discretion is, by definition, not of benefit to the private sector. ${ }^{19}$ In the terminology of the ADB study, it is argued that if economic potential is to be realized, the function of allocating resources should increasingly be performed by the market, rather than the state; and the procedural functions of legal systems must move from the discretionary end of the continuum towards the rule-based end.

\section{Room for variety}

The normative undertones of legal reform policy, although not unusual in the development field, are particularly striking given that the suggestion that discretion should be limited is one of the most politically charged 'economic' conclusions ever drawn by a development organization. The institutional school of economics, upon which the World Bank relies, teaches that 'there is no unique efficient result' of the interaction between legal systems and the economy. ${ }^{20}$ The very notion of seeking an ideal-type legal system for supporting FDI seems to go against this fundamental institutionalist rule: first, in that it dictates that such a search is desirable; and second, in that it seeks to define a set of criteria according to which a legal system should be measured. If institutions 'matter economically in the actual costs (and benefits) they create for businesses, not in their compliance with ideal forms', then institutions must be assessed according to their effect on the 'efficiency of economic transactions,' rather than on the extent of 'their resemblance to rational Western norms of law and jurisprudence'. ${ }^{21}$

As David Campbell explains, technically, the definition of 'justice based on the rule of law as predictability ... can embrace a wide range of political regimes. Obviously, some tyrannies are of their nature unpredictable, and so cannot construct a legal system which is just' according to this definition. But:

[T] he argument for the extension of the rule of law based on the facilitation of economic development typically does not follow the technical argument for the rule of law as predictability through to its politically agnostic, amoral

18 World Bank, World Development Report 1996: From Plan to Market (1996) at 9397; and World Bank, World Development Report 1997: The Role of the State in a Changing World (1997) at 8 and 103-6.

19 Tshuma, op. cit. n. 3, p. 78. See, also, A. Perry, Legal Systems as a Determinant of FDI: Lessons from Sri Lanka (2001) at ch. 3.

$20 \mathrm{~N}$. Mercuro and S. Medema, Economics and the Law: From Posner to Post Modernism (1997) at 118.

21 A. Stone et al., 'Public Institutions and Private Transactions: a Comparative Analysis of the Legal and Regulatory Environment for Business Transactions in Brazil and Chile' in Empirical Studies in Institutional Change, eds. L. Alston et al. (1996) at 95, 95-9. 
conclusion. It typically is not envisaged that the rule of law will operate neutrally in respect of the political regime in which it is established. It typically is argued that it will change that regime, ultimately bringing it more into conformity with the bourgeois social structure of the advanced capitalist economies ... The neoclassical developmental strategy ... now turns on geographical 'universalization', or 'globalization' as it commonly is put, of private enterprise, and specifically the development within the Orient of the rationalization of the Occident ... [T] here is nothing that Weber would have regarded with more horror. ${ }^{22}$

Obviously, an acknowledgement of the existence of differences in the relationship between the private sector and states across the world is at the heart of the current legal reform agenda. Indeed, the World Bank and other development organizations have regularly noted that legal reform must be tailored to local culture, politics, and history; states must have ownership of and involvement in their legal reform programmes; and therefore, there is no 'simple guide for building [a legal system] to meet the needs of all peoples'. ${ }^{23}$ Therefore, 'the drafting of laws to fit the local legal culture and constitutional requirements is a specialised legal skill'.24

It is nonetheless difficult to find concrete examples of such flexibility in legal reform programmes. Instead, development organizations have resorted to the adoption and promotion of a normative market-allocative rule-based model. Until recently, there has been little attempt to create any systematic way of discussing, let alone predicting, variations upon that model. As a World Bank publication has noted, the measurement of governance during the early years was largely anecdotal. ${ }^{25}$ This is now changing, as the World Bank is currently developing a number of tools for measuring differences between the operation of legal systems. It has collected data from a wide variety of sources (risk assessment agencies, multilateral organizations, think tanks, and other NGOs $)^{26}$ in order to document differences in the following areas: voice and accountability, political instability and violence, government effectiveness, regulatory burden, rule of law, and control of corruption. ${ }^{27}$ However, very little attention has been paid to determining what the private sector really wants from legal systems. If indeed the private sector should get what it wants, surely it is important to find out what that is.

22 Campbell, op. cit., n. 17, pp. 21-26.

23 I. Shihata 'Preface: Good Governance and the Role of Law in Economic Development' in Making Development Work, eds. A. Seidman et al. (1999) xviixxiv. See, also Perry, op. cit., n. 19, ch. 3.

24 C. Gray, 'Reforming Legal Systems in Developing and Transition Countries' in Seidman et al., id., at p. 63.

25 D. Kaufmann et al., 'Governance Matters: From Measurement to Action' (2000) 27 Finance and Development 10, at 10.

26 id. and D. Kaufmann et al., 'Aggregating Governance Indicators', World Bank Policy Research Working Paper no. 2195 (1999). These papers, and the data sets on which they rely, can be found at <www.worldbank.org/wbi/governance>.

27 Kaufmann et al., op. cit., n. 25, p. 10. 


\section{DEFINING AND MEASURING THE RELATIONSHIP BETWEEN CULTURE, LEGAL SYSTEMS, AND ECONOMIC DEVELOPMENT}

As Roger Cotterrell notes, legal sociologists and anthropologists have generally failed to define adequately the concept of 'legal culture'. For example, it is often unclear which aspects of culture are considered to be specifically 'legal' and what is not; at what levels (for example, family, ethnic group, profession, nationality) independent legal cultures can be said to exist; and what is the purpose of developing the concept in the first place. As a result, the concept of 'legal culture' is generally too imprecise either to be subjected to empirical measurement, or to be of significant use to legal theory. ${ }^{28}$ For the purposes of this paper, the term 'culture' is intended to refer to the values that economic actors carry with them as a result of their personal experience, and according to which they make economic decisions. In the context of its relationship with legal systems and economic development, 'culture' is intended to refer to those values which might be expected to affect economic actors' perceptions and expectations of legal systems.

Although he is generally cautious about the wisdom of subjecting cultural variance to empirical measurement, Cotterrell does suggest that such efforts might yield useful results in some circumstances. He argues that by describing legal cultures in terms of "pure or ideal types (that is, logically constructed concepts deliberately designed not to represent empirical reality but to organise interpretation of it)' researchers can make useful comparisons between different legal cultures, without denying the existence of variations within each 'type' ${ }^{29}$ For example, Cotterrell notes the efforts of Mirjan Damaska "to "disaggregate" what might be thought of as very general differences in legal culture as between common law and civil law procedural systems'. Instead, Damaska considers legal systems with reference to new ideal types. These ideal types are based upon differences in 'ideas that are capable of moulding forms of justice into recognisable patterns', and logical relationships between those ideas. ${ }^{30}$ Hofstede's work (and the manner in which it is used in this paper) seeks to achieve a similar balance.

Hofstede's research into cultural variance is based primarily upon the results of a massive survey (over 116,000 questionnaires including over 100 standardized questions) administered (in 1968 and again in 1972) to IBM

28 R. Cotterrell 'The Concept of Legal Culture' in Comparing Legal Cultures, ed. D. Nelken (1997) 13-29, at 13-21.

29 id., pp. 24-5.

30 id., p. 24. Cotterrell also argues (id., p. 25) that 'where relevant cultural aggregates are small scale and isolated', it 'may be feasible ... to attempt to describe and record, ethnographically, in all its richness and complexity, a cluster or aggregate of attitudes, customs and patterns of social action such as might make up ... legal culture'. 
employees from fifty countries and three multi-country regions, working in seventy-two subsidiaries. ${ }^{31}$

Statistical analysis of the data revealed four main dimensions along which cultural attitudes vary. That is, answers to questions relating to these four dimensions tended to be strongly correlated with the nationality of the respondent. The dimensions were: degrees of social equality (power distance); individualism versus collectivism; assertiveness (masculinity) versus modesty (femininity); and ways of dealing with uncertainty. According to Hofstede, these dimensions corresponded 'amazingly well' with those identified in 1954 by sociologist Alex Inkeles and psychologist Daniel Levinson. ${ }^{32}$ A fifth dimension of 'long-term versus short-term orientation' was later identified during research into Confucian values by Michael $\mathrm{H}$. Bond and his 'Chinese Culture Connection' team. ${ }^{33}$ Before moving on to discuss the possible relevance of Hofstede's findings to the relationship between legal systems and economic growth, it is necessary to explain in greater detail his methodology and where it fits into the controversies which plague empirical work in this field.

Responses for each nationality/region on each dimension were ranked and converted into relative scores. The scoring system was devised using a formula which forced the scores to range roughly from zero to 100. It is important to emphasize that since the rankings and scores are relative, they only tell us about the nature of cultural attitudes of one country relative to another. ${ }^{34}$ The contribution of Hofstede's analysis is to allow us to plot and compare a five-dimensional picture of the 'mental software' of people from each country/region. It does not tell us absolutes. ${ }^{35}$ It is also important to

31 Hofstede, op. cit., n. 2, p. 251. Those interested in understanding the methodology of the study in greater detail should consult G. Hofstede, Cultures Consequences: International Differences in Work-Related Values (1980).

32 id., pp. 13-14. As Hofstede notes (id., p. 14) the validity of these dimensions is strengthened by the fact that they are remarkably similar to those predicted by other researchers in the past. His findings are continually cross-referenced with those of other studies by psychologists, sociologists, and anthropologists.

33 id., p. 161. Questionnaires were devised by Chinese researchers in order to identify issues of importance to Confucian societies, and administered to 100 students in twenty-three countries. The research appears in The Chinese Culture Connection (a team of 24 researchers), 'Chinese Values and the Search for Culture-Free Dimensions of Culture' (1987) 18 J. of Cross Cultural Psychology 143. More recently, Niels Noorderhaven and Bassirou Tidjani have begun to look for Africaspecific cultural values in 'Culture, Governance and Economic Performance: An Explorative Study with a Special Focus on Africa' (2001) 1 International J. of Cross Cultural Management 31-52.

34 Hofstede, op. cit., n. 2, pp. 24, 53, 82, and 113.

35 The importance of the distinction between relative and absolute measurements can be illustrated using the concepts of absolute poverty (of which malnourishment could be an indicator) and relative poverty (of which having one car, as compared to your neighbour's two cars, could be an indicator). 
note that like Damaska, Hofstede constructed his analytical system from the bottom up. However, unlike Damaska, Hofstede uses dimensions, rather than strict ideal types. As Hofstede explains, '[i]n practice, typologies and dimensional models can be considered as complementary. Dimensional models are preferable for research, but typologies for teaching methods'. He (and this paper) therefore adopts a typology approach to explaining the dimensions revealed by the data. He (and this paper), 'describes the two opposite extremes, which can be seen as ideal types' for each dimension, but as the scores show, 'most real cases are somewhere in between the extreme pictured' ${ }^{36}$

It remains to address two general criticisms which some commentators might be expected to level at Hofstede's work. The first criticism is that much empirical work in the field of culture theory relies primarily on distal, rather than proximal variables. ${ }^{37}$ This is true of Hofstede's work. For example, he does not ask respondents directly about their attitudes to uncertainty. Instead, his conclusions about attitudes to uncertainty are based upon information such as how long respondents expected to continue working for IBM, and whether respondents agreed with the statement that 'company rules should not be broken even when the employee thinks it is in the company's best interest'. ${ }^{38}$ This is problematic since some would argue that '[p]roximal variables are usually far more efficient in accounting for behaviour than distal variables.' Indeed, some would go so far as to say there is 'tremendous difficulty in accounting for anything by means of distal variables'. ${ }^{39}$ On the other hand, others would argue that the use of proximal variables introduces the problem of social desirability by encouraging answers which are intended by respondents to be more socially acceptable than accurate.

The second criticism relates to the capacity in which respondents provide information. Hofstede's material was collected from employees of IBM, and was designed to test their values in that capacity. Some might argue that the material should not be used for any other purpose. Social relations 'differ, depending on which group membership is considered: work group, family or leisure. If a person responds to a questionnaire, which role is he or she adopting?' This may depend upon many factors, including the 'contents of the questionnaire, the setting in which it is administered and its stated purpose' ${ }^{40}$ However, Hofstede felt that the size and depth of the survey allowed him to draw broader conclusions about national value systems. Even

36 Hofstede, op. cit., n. 2, p. 15.

37 L. Sjoberg, 'Explaining Risk Perception: An Empirical Evaluation of Cultural Theory' in The Earthscan Reader in Risk and Modern Society, eds. R. Lofstedt and L. Frewer (1998) 115, at 116.

38 Hofstede, op. cit., n. 2, p. 112.

39 Sjoberg, op. cit., n. 37, p. 116.

40 id., pp. 116-17. 
if the IBM working environment might affect responses, the fact remains that since the respondents were all 'functionally equivalent' IBM employees and varied only in terms of nationality, the latter is the only variable which could account for differences in response. ${ }^{41}$ Ultimately, it seems better to proceed with caution, than to simply ignore such a unusually large and detailed data set.

\section{VARIATIONS IN 'MENTAL SOFTWARE'}

This paper does not attempt to cover the full range of Hofstede's findings. Instead, it focuses on the three dimensions (power distance, individualism, and ways of dealing with uncertainty) which seem most relevant to the study of the relationship between legal systems and economic activity. Furthermore, scores for each dimension are given only for the following selection of countries: Britain, Hong Kong, ${ }^{42}$ India, Japan, France, the Philippines, Pakistan, Taiwan, and the United States. The countries represent a range of stages of economic development and geographical locations in the West,

\section{Table 1: Hofstede Rankings by Region and Stage of Economic Development*}

$\begin{array}{lll}\begin{array}{l}\text { Uncertainty } \\ \text { Avoidance } \\ \text { (UAI) }^{43}\end{array} & \begin{array}{l}\text { Individualism } \\ (\text { IDV })^{44}\end{array} & \begin{array}{l}\text { Power } \\ \text { Distance } \\ (\text { PDI })^{45}\end{array}\end{array}$

\begin{tabular}{|c|c|c|c|c|}
\hline 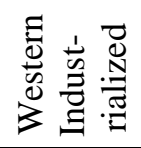 & $\begin{array}{l}\text { Great Britain } \\
\text { France } \\
\text { USA }\end{array}$ & $\begin{array}{l}47 / 48 \\
10 / 15 \\
43\end{array}$ & $\begin{array}{l}3 \\
10 / 11 \\
1\end{array}$ & $\begin{array}{l}42 / 44 \\
15 / 16 \\
38\end{array}$ \\
\hline 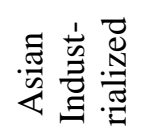 & $\begin{array}{l}\text { Hong Kong } \\
\text { Japan } \\
\text { Taiwan }\end{array}$ & $\begin{array}{l}49 / 50 \\
7 \\
26\end{array}$ & $\begin{array}{l}37 \\
22 / 23 \\
44\end{array}$ & $\begin{array}{l}15 / 16 \\
33 \\
29 / 30\end{array}$ \\
\hline 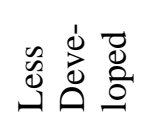 & $\begin{array}{l}\text { India } \\
\text { Pakistan } \\
\text { Philippines }\end{array}$ & $\begin{array}{l}45 \\
24 / 25 \\
44\end{array}$ & $\begin{array}{l}21 \\
47 / 48 \\
31\end{array}$ & $\begin{array}{l}10 / 11 \\
32 \\
4\end{array}$ \\
\hline
\end{tabular}

* Shaded areas indicate range of over 10 within regional/developmental group.

41 Hofstede, op. cit., n. 2, p. 251.

42 Hong Kong is treated as a 'country' because Hofstede's data was collected before the handover of Hong Kong to the People's Republic of China.

43 Hofstede, op. cit., n. 2, p. 113. Rankings out of 53.

44 id., p. 53. Rankings out of 53.

45 id., p. 26. Rankings out of 53. 
South Asia and East Asia, and have been chosen in order to give a flavour of Hofstede's findings.

Table 1 sets out the data for the nine selected countries, divided by region and stage of economic development, along the three selected cultural dimensions. Shaded areas indicate a difference of over ten ranks (of a possible fifty-three) within the regional/developmental group. These include all but the scores of Western industrialized nations as they relate to individualism. The definition and precise implications of each index will be described in detail below. At this point, the conclusion to be drawn from this rough indicator is that cultural differences exist even as between countries of similar region and/or stage of economic development.

In the following sections, Hofstede's findings will be analysed for evidence of the potential impact of mental software on (a) the importance of legal systems and (b) the core components of an effective legal system. Particular attention will be paid to Hofstede's comments relating to three key areas: relationships between individual economic actors, the structure of legal systems, and interactions between individual economic actors and the state.

\section{VARIATIONS IN LEVELS OF LEGALISM}

The Washington Consensus places a heavy emphasis on the existence of clear laws which detail the rules of engagement among economic actors and between economic actors and the state, and which are fully enforced. This approach is apparent in the Foreign Investment Advisory Service (FIAS) methodology for assessing the need for reform of legal systems. The FIAS examines 'what is required [of individual economic actors] for full compliance with all existing laws and regulations' ${ }^{46}$ Similarly, De Soto's influential study of the costs of bureaucracy documented the number of steps and the costs required to enter and remain in the formal business world in Peru, ${ }^{47}$ but did not assess whether alternative mechanisms had been developed to speed up or smooth out the process of 'going formal' and if so, how much those alternative routes cost. ${ }^{48}$

But it is not clear that such a legalistic approach is uniformly suitable. For example, the 1998 ADB study found that 'litigation rates vary considerably across economies,' and that the 'variation cannot be explained by economic development, or the extent to which division of labour has been achieved in these economies'. It found that 'litigation rates in Japan in particular have remained much lower than in other high performing economies. Nor do institutional constraints explain differences in litigation rates'. A comparison

46 Foreign Investment Advisory Service (FIAS) Administrative Barriers <www.fias.net/services/barriers.htm>, visited December 1999. Emphasis added.

47 H. De Soto, The Other Path (1989) at 134.

48 Stone et al., op. cit., n. 21, p. 105. 
of litigation rates in Japan and Taiwan 'demonstrates that even when we control for shared civil law tradition and legacy of state imposed ceilings for the legal profession, litigation rates vary considerably'. The team therefore declared itself unable to 'solve this puzzle of persistent divergence'. ${ }^{49}$

Hofstede's findings indicate two possible avenues of research which might help to resolve the quandary identified by the ADB. As will be shown in the following subsections, inter-cultural variations in attitudes to uncertainty and in levels of individualism might explain apparent variations in the importance of legal systems.

\section{Attitudes to uncertainty}

According to Hofstede, the 'need for laws and rules is not based on formal logic but on psycho-logic' in particular, the psychological need for certainty. ${ }^{50}$ This is precisely the kind of nuance which is likely to escape consideration under the blackboard approach.

The term 'certainty' describes the extent to which risk is capable of measurement. The term 'risk' describes the measurement of both the probability that an outcome will occur, and the likely impact of that outcome upon the economic actor. Where the level of risk is known, economic actors can form legal relationships which cover most possibilities, and which carry appropriate valuations of obligations. ${ }^{51}$ In theory, it does not matter that economic actors do not know precisely which outcome the future holds, as long as 'all the alternative possibilities are known and the probability of the occurrence of each can be accurately ascertained'. Furthermore, where an outcome has a known risk of occurring, 'it does not especially matter even whether the proportion is large or small. The loss becomes a fixed cost in the industry and is passed on to the consumer'. ${ }^{52}$

However, problems may arise in the context of uncertainty that is, when there is a lack of credible data from which to calculate the likelihood of change, and the likely impact of that change upon an economic decision. ${ }^{53}$ In the context of uncertainty, risk cannot be quantified. It is therefore presence or lack of credible information which distinguishes risk, which is not a problem, from uncertainty, which is a problem. ${ }^{54}$ In theory, a firm will invest in a high-, medium-, or low-risk enterprise where there is high degree of certainty (such that the risk surrounding an investment can be quantified and costed) but the higher the uncertainty, the less likely it is that any investments will be made.

49 Pistor and Wellons, op. cit., n. 13, p. 215.

50 Hofstede, op. cit., n. 2, pp. 120-1.

51 A. Belcher, 'The Boundaries of the Firm: The Theories of Coase, Knight and Weitzman' (1997) 17 Legal Studies at 25.

52 F. Knight, Risk, Uncertainty and Profit (1921) at 198 and 213.

53 Belcher, op. cit., n. 51, p. 25.

54 Knight, op. cit. n. 52, p. 198. 
This proposition is supported by the Borner et al. study, which showed strong correlations between political credibility, as perceived by the private sector, and investment levels: countries with high perceived political credibility had high investment rates, and vice versa. ${ }^{55}$ The study argues that in a credible state economic actors are more confident, and therefore more prone to making investments, because they can 'readily predict the vagaries of the future and be reasonably assured of continued free competition'. ${ }^{56}$ From this we can conclude that the predictability (or certainty) of a legal environment may be an important factor in determining economic growth rates.

Uncertainty is a fact of life in any society. Where societies differ is in the extent to which they seek to avoid uncertainty, and in their choice of uncertainty-reduction tool, such as law. The amount and content of laws 'continue to vary' from country to country, and show 'no signs of spontaneous convergence', despite 'the availability of the same information virtually anywhere around the globe'. According to Hofstede, this is because attitudes to uncertainty vary across cultures, and these attitudes are 'not based on formal logic but on psycho-logic' ${ }^{57}$

Hofstede's Uncertainty Avoidance Index (UAI, Chart 1) measures 'the extent to which the members of a culture feel threatened by uncertain or unknown situations' ${ }^{58}$ Since the UAI score is only relative, these findings do not show that the Japanese are completely intolerant of any uncertainty, nor that people from Hong Kong will tolerate total uncertainty. What they do illustrate is that certainty, and perhaps therefore legal systems, will be of varying degrees of importance in different countries. People from countries with a high UAI score tend to have an 'emotional' need for rules; to believe that 'as little as possible should be left to chance'; to 'shun ambiguous situations'; and to 'look for a structure in their organizations, institutions and relationships which makes events clearly interpretable and predictable' ${ }^{59}$ As a result, countries with high UAI scores tend to have more precise laws than those with low UAI scores. For example, while Germany (UAI score of sixty-

55 S. Borner et al., Political Credibility and Economic Development (1995) at 62-71. A later study for the World Bank (World Bank, op. cit. (1997), n. 18, pp. 4-5, 32, and 43) produced similar results. Private sector perceptions of the credibility of governments were found to deteriorate (along with investment levels) in the following order: OECD, South and South-east Asia, Middle East and North Africa, Central and Eastern Europe, Latin America and Caribbean, Sub-Saharan Africa and Commonwealth of Independent States.

56 Borner et al., op. cit., n. 55, p. 16. See also Shihata, op. cit., n. 23, p. xxiii; World Bank, op. cit. (1996), n. 18, pp. 85-9; and World Bank, op. cit. (1997), n. 18, p. 43.

57 Hofstede, op. cit., n. 2, pp. 110-11, 120-1.

58 id., p. 113.

59 id., pp. 116 and 120-1. Hofstede goes on to stress that a person who avoids uncertainty does not necessarily avoid risk. People from uncertainty avoiding cultures 'are often prepared to engage in risky behaviour in order to reduce ambiguities, like starting a fight with a potential opponent rather than sitting back and waiting.' Once the fight has become a reality, uncertainty is effectively dispelled. 
five) 'has laws for the event that all other laws might become unenforceable', Great Britain (UAI score of thirty-five) 'does not even have a written constitution'. ${ }^{60}$ Rules and 'rule-oriented behaviours' in high UAI countries are often 'clearly non-sensical, inconsistent, or dysfunctional'. This is because 'even ineffective rules satisfy people's emotional need for formal structure. What happens in reality is less important'. By contrast, low UAI countries have 'an emotional horror of formal rules' and resort to them only 'in case of absolute necessity'. Paradoxically, 'although rules in countries with weak uncertainty avoidance are less sacred, they are generally more respected' ${ }^{61}$

The politics of high UAI societies lean to the right, with an emphasis on law and order. Citizens in these countries are 'pessimistic about their possibilities of influencing decisions made by authorities', and tend to be less likely to protest against the state. They 'are not only more dependent on the expertise of the government, but they also seem to feel that this is how things should be'. By contrast, citizens in weak uncertainty avoidance countries (low UAI score) 'believe they can participate in political decisions at the lowest, local level', are more prepared to protest against the state. ${ }^{62}$

\section{Chart 1. Uncertainty Avoidance Index (UAI) ${ }^{63}$}

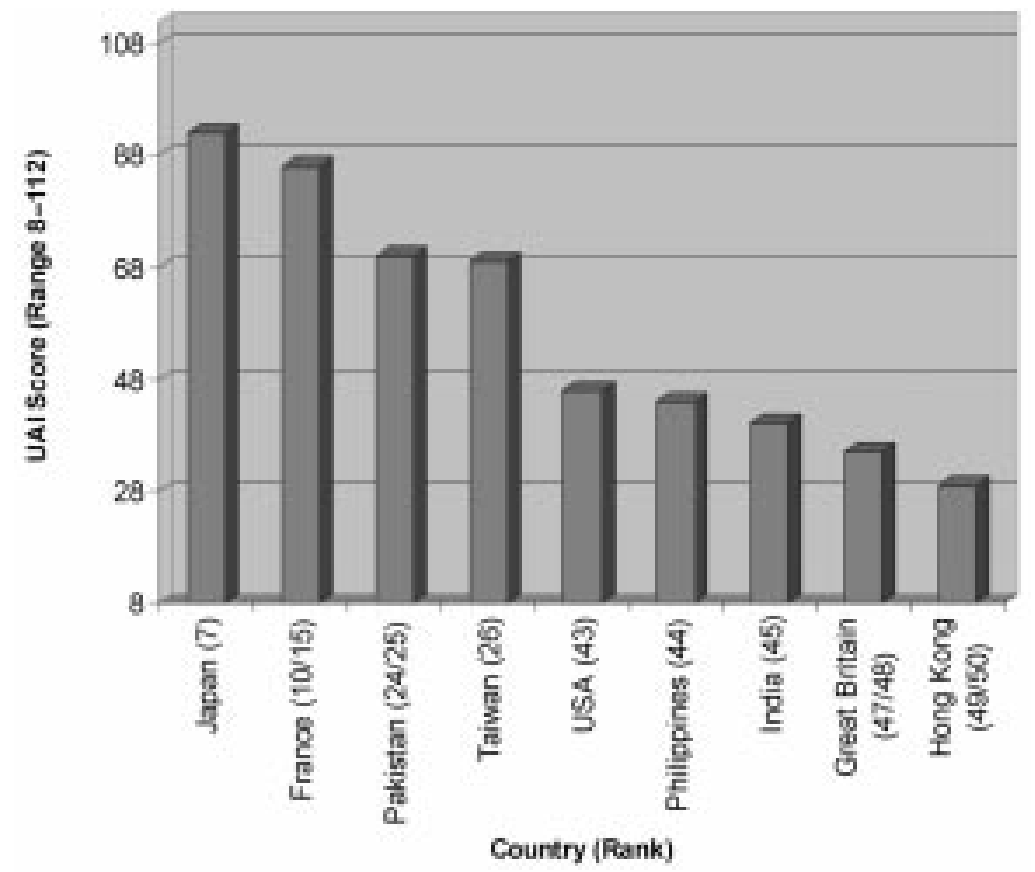

60 id., p. 126.

61 id., pp. $120-1$.

62 id., pp. $127-8$.

63 id., p. 113. 
Attitudes to uncertainty do not appear to be inextricably linked to either geographical location or economic development. ${ }^{64}$ For example, the Japanese have the highest UAI score of the nine selected countries (ninety -two), while people from Hong Kong have the lowest UAI score of the selected countries; and the score of India (forty) is closer to that of Great Britain (thirty-five) than to that of Pakistan (seventy). However, in some countries the roots of uncertainty avoidance may be located in historical connections to the Roman Empire (for example, France, high UAI score) and the Chinese Empire (for example, Taiwan, low UAI score). While the Roman Empire produced uniformly applicable codified laws, the Chinese Empire 'never knew this concept of law' and instead operated according to general principles. ${ }^{65}$

The implications of the UAI for this paper are that attitudes to uncertainty appear to vary in complex - and therefore as yet unpredicatable - ways; that variations in attitudes to legal systems have been identified at the general level, but not explored, by development organizations; and that one method of exploring this area might be to treat legal systems as a tool for uncertainty-reduction, thus opening the door to build upon the existing methodology and findings of cultural theory.

\section{Individualism}

Hofstede's Individualism Index (IDV, Chart 2) tells us about the extent to which people think of themselves primarily as an individual; or as a member of a group. ${ }^{66}$ Hofstede notes that economics is essentially an 'individualist science' dominated by thinkers from 'strongly individualistic countries' such as the United Kingdom and the United States, and whose 'assumptions are unlikely to apply' in collectivist societies, in which the interests of the group are placed above those of the individual. ${ }^{67}$ Again, this is a distinction which is unlikely to register on the blackboard economics radar.

64 id., p. 136. However, a weak negative correlation was found between UAI and wealth - that is, stronger uncertainty avoidance scores were slightly more likely to be found in poorer countries.

65 id., p. 135.

66 id., pp. 49-54. IDV scores were based on responses to questions such as: 'Try to think of those factors which would be important to you in an ideal job; disregard the extent to which they are contained in your present job. How important is it to you to ... Have a job which leaves sufficient time for your personal or family life. ... Have considerable freedom to adopt your own approach to the job' and so on. As Hofstede notes, these issues do not cover the full range of distinctions between individualism and collectivism in society. However, correlations between these IBM findings and studies of 'other characteristics of societies confirm (validate) the claim that this dimension from the IBM data does, indeed, measure individualism: at pp. 51-2.

67 id., p. 72. 


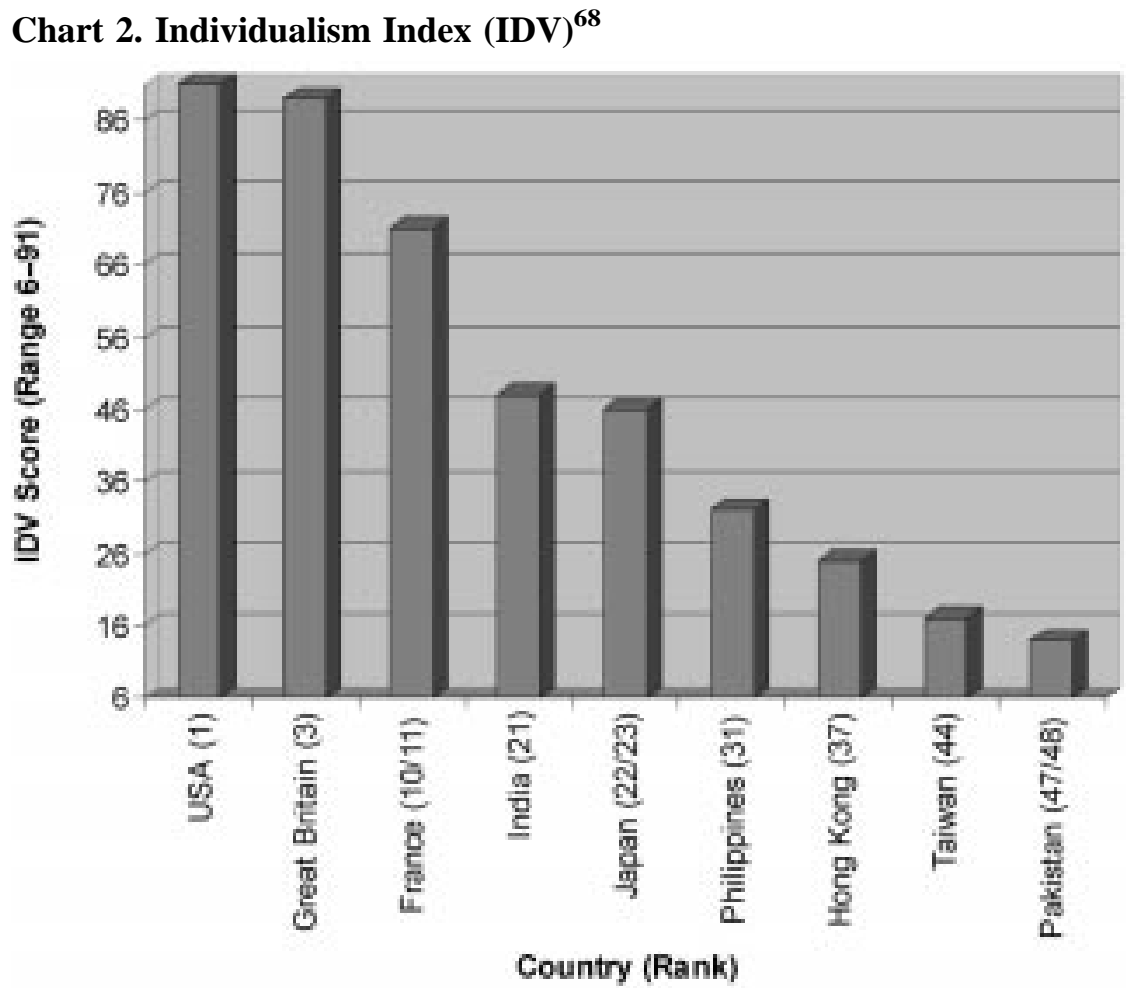

The market-allocative rule-based model places a heavy emphasis on the existence of laws (such as those governing contracts) which support private economic arrangements. However, in some societies, non-contractual methods of doing business are equally if not more important. For example, it has been argued that Japanese economic activity relies upon notions of community and 'networks of trust'; Chinese (including Taiwanese) businesses rely on personal connections, 'reciprocal obligations and longterm negotiating relationships; and Korean business people favour "cooperation" over more legalistic relationships'. ${ }^{69}$

One explanation for this disparity is provided by Hofstede's finding that these societies are all relatively collectivist (low IDV score). In a collectivist society, 'the personal relationship prevails over the task and should be established first'. By contrast, in an individualist society (high IDV score), 'the task is supposed to prevail over any personal relationships'. Having made in investment in personal relationships, the collectivist has a foundation of understanding and trust on which to build. This phenomenon

68 id., p. 53.

69 J. Gray, False Dawn: The Delusions of Global Capitalism (1998) at 169 and 183-5. See, also, Perry, op. cit., n. 19. 
was noted by sociologist Cas Vroom, who "contrasts the Western orientation towards "return on investment" with an Indonesian "return on favors".' As a result, many things "which in collectivist cultures are self-evident must be said explicitly in individualist cultures'. For example, 'American business contracts are much longer than Japanese business contracts'. Furthermore, the 'naive Western businessman who tries to force quick business in a collectivist culture condemns himself to the role of outgroup member and to negative discrimination'. Interestingly, Hofstede notes that the 'weaker the individualism in the citizens' mental software, the greater the likelihood of the state having a dominating role in the economic system' ${ }^{70}$ In the terminology of the ADB study, collectivist cultures are more likely to have state-allocative legal systems.

Generally speaking, societies that are wealthy, urbanized, and industrialized tend to be more individualist (high IDV score); while societies that are poor, rural, and traditional tend to be more collectivist (low IDV score). But significantly, the exceptions to this rule come from East Asia: Japan, South Korea, Taiwan, Hong Kong, and Singapore combine collectivist societies with wealth, industrialization, and urbanization. ${ }^{71}$ Collectivism, with its low legalism, appears to work for East Asian economies.

According to Hofstede's statistical analysis, it would seem that wealth tends to cause individualism, rather than vice versa. This does not mean that differences in individualism between states will disappear, because "cultures shift, but they shift together, so that the differences between them remain intact'. $^{72}$

\section{Combined effect of individualism and attitudes to uncertainty}

The IDV may indicate where rules (that is, uncertainty reduction tools) in strong UAI countries will tend to come from. Countries that combine strong uncertainty avoidance with individualism (for example, France) tend to favour rules that are 'explicit and written'; while countries which combine strong uncertainty avoidance with collectivism (for example, Japan) tend to favour rules which are 'implicit and rooted in tradition' ${ }^{73}$ Those who believe that laws make society rather than vice versa might argue the reverse causal relationship - countries with lots of explicit rules tend to become intolerant of uncertainty and very individualistic. Either way, there are clear and logical reasons to argue that the existence of a relationship is likely and thus deserves exploration by development organizations.

70 Hofstede, op. cit., n. 2, pp. 60, 67-8, and 72.

71 id., p. 74.

72 id., pp. 76 and 77.

73 id., p. 128. As Hofstede notes (p. 28) this contrast 'represents a bone of contention in the negotiations between Western countries and Japan about the opening up of the Japanese markets for Western products. The Japanese rightly argue that there are no formal rules preventing the foreign products from being brought in; but the would-be 
As explained above, the Washington Consensus argues that certainty (alternatively described as predictability and credibility) is only truly achieved where discretionary powers of the state and individual bureaucrats are limited. Crucially, economic actors are rarely given the opportunity to identify any positive results of wide bureaucratic discretion. For example, the Borner et al. survey upon which many aspects of World Bank policy have relied asked domestic and foreign investors whether they could use bribes or personal contacts to influence the speed and or outcome of a bureaucratic or judicial process. Answers in the affirmative were taken to indicate low state credibility. Respondents were not given an opportunity to indicate whether or not they perceived or expected such access to the state to provide certainty. ${ }^{74}$

Even if it was agreed that all societies require a basic level of certainty, variations across cultures might nonetheless arise from the fact that certainty is in the eye of the beholder. It may be true that 'arbitrary decisions prove to be one of the biggest disincentives to investors' ${ }^{75}$ but decisions which may appear to be arbitrary to some may be perfectly predictable to others. As a consequence, there is no clear reason why certainty should only be achievable through limiting discretion.

\section{The power distance index}

Hofstede's Power Distance Index (PDI, Chart 3) tells 'us about dependence relationships in a country' - that is, 'the extent to which the less powerful ... expect and accept that power is distributed unequally'. While the UAI points to differences in the 'distribution of competence' between citizens and the state, the PDI discloses differences in the distribution of power between citizens and the state. ${ }^{76}$ The PDI may therefore provide an insight into whether broad state discretion is expected and positively perceived by the private sector in different cultures.

In small power distance countries (low PDI score, for example, Great Britain), 'a feeling dominates that the use of power should be legitimate and subject to the judgement between good and evil'; that inequality is 'basically undesirable' and, although unavoidable, 'it should be minimised by political means'; and that the 'law should guarantee that everybody, regardless of

Western importers find themselves up against the implicit rules of the Japanese distribution system which they do not understand'.

74 Borner et al., op. cit., n. 55, p. 176.

75 J. Stopford et al., Rival States, Rival Firms: Competition for World Market Shares (1991) at 126. See, also, Borner et al., id., p. 16.

76 Hofstede, op. cit., n. 2, pp. 27, 28, and 126-7. 
Chart 3. Power Distance Index (PDI) ${ }^{77}$

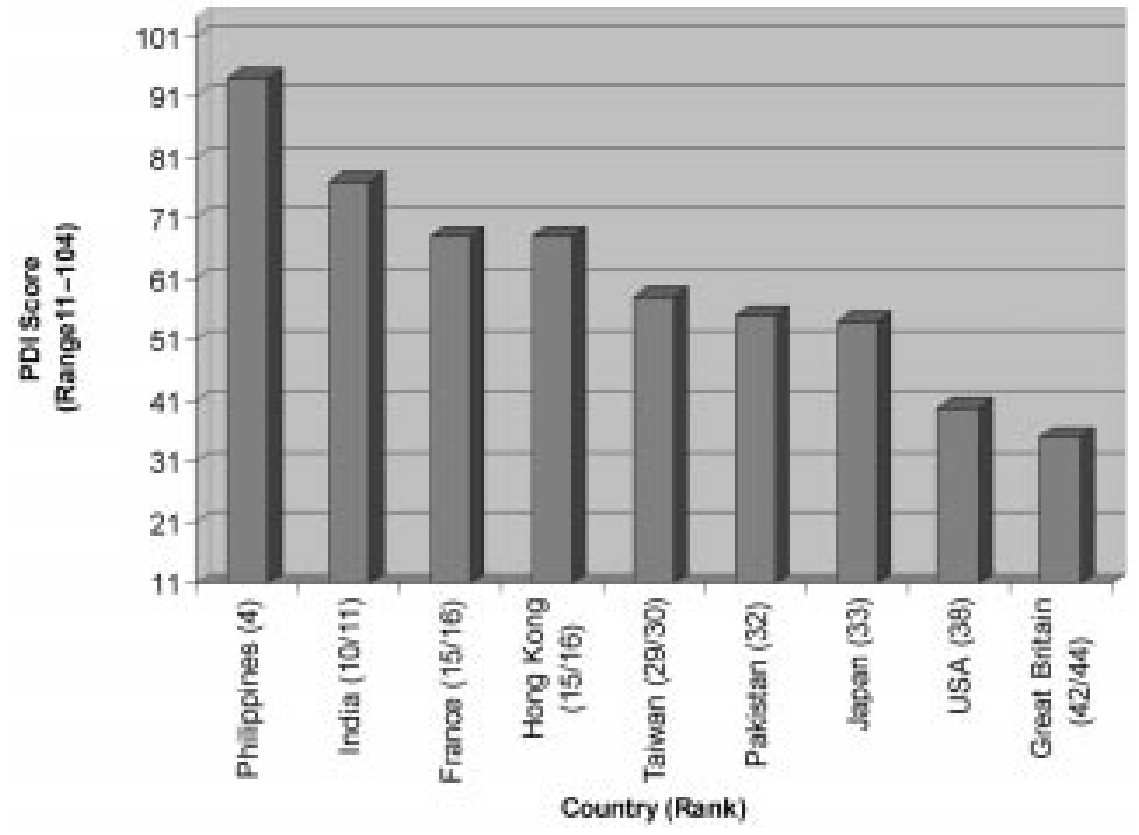

status, has equal rights' ${ }^{78}$ In the terminology of development policy, small power distance countries are characterized by rule-based (less discretionary) states.

In large power distance countries (high PDI score, for example, the Philippines), 'power is seen as a basic fact of society which precedes the choice between good and evil', and '[i]ts legitimacy is irrelevant' because '[m]ight prevails over right'. 'There is an unspoken consensus that there should be an order of inequality in this world in which everyone has his or her place. Such an order satisfies people's need for dependence and it gives a sense of security both to those in power and to those lower down' ${ }^{79}$ In the terminology of the development organizations, large power distance cultures are characterized by more discretionary states.

Importantly for the purposes of this paper, in large power distance countries 'the exercise of discretionary power by superiors replaces, to some extent, the need for internal rules' ${ }^{80}$ Therefore, to the extent that certainty is necessary, it may be achieved either by broad discretion or by limited 
discretion. Although the private sector may 'call loudly for clear, unambiguous rules', 'continuity of policy', and decisions which are 'not capricious', it may also recognize the benefits of a government which has the ability 'to be flexible, to discriminate in its favour', and will want to be 'free to take advantage of any shifts in the factors which improve its own bargaining power' ${ }^{81}$

That greater power distance is not necessarily damaging to the economy is evidenced by the fact that France and Hong Kong are both highly successful, medium power distance economies. Furthermore, the division between small and large power distance cultures (and levels of state discretion) is not complete, and some countries exhibit both extremes. 'A country like Spain, ruled dictatorially until the 1970s, has shifted remarkably smoothly to a pluralistic government system'; while in Britain, with its low PDI score, the government tried to suppress publication of sensitive information contained in the book Spycatcher. ${ }^{82}$ Therefore, different levels of power distance, and consequently of state discretion, may be required or expected for different functions or at different times. This suggestion is supported by the 1998 ADB study's conclusion that in periods when the Asian states actively controlled the economy, legal systems 'based on state-allocative law and discretionary procedures supported activities key to economic policy'. ${ }^{83}$ A 1996 ADB study also noted that autocratic regimes with broad discretionary powers can be more effective than liberal states in enforcing the rule of law, and encouraging commercial transactions. ${ }^{84}$ The 1998 ADB study suggested that perhaps a market-allocative rule-based legal system 'can have a measurable effect on future economic development only after economies have reached a certain threshold of development'. ${ }^{85}$ To this one might add that perhaps the effect of such a legal system might be constrained by the private sector's cultural values.

According to Hofstede's statistical analysis, the following factors appear to contribute to a country's PDI score: geographical latitude (higher latitude, lower PDI); population size (higher population, higher PDI); and its wealth (higher wealth, lower PDI). ${ }^{86}$ The roots of variation in power distance relationships may well be historical. Government under the Roman and the Chinese empires (medium to high PDI score) was highly centralized, 'which presupposes a population prepared to take orders from the center'. By

81 Stopford et al., op. cit., n. 75, pp. 13 and 135.

82 Hofstede, op. cit., n. 2, p. 39.

83 Pistor and Wellons, op. cit., n. 13, p. 107.

84 H. Root, Small Countries, Big Lessons: Governance and the Rise of East Asia (1996) at pp. $170-1$.

85 Pistor and Wellons, op. cit., n. 13, p. 111.

86 Hofstede, op. cit., n. 2, pp. 44-6. However, Hofstede notes (pp. 44-5) that such statistical relationships do not prove the direction of causality, nor whether both of these factors are in fact caused by a third common factor. So, (with the obvious exception of geographical location) it is not clear whether the PDI score causes or is caused by these factors, or some other factor. 
contrast, government in the Germanic part of Europe (low PDI score) was far more localized. As for the future of variation in power distance, Hofstede notes that a comparison of data collected in 1968 and 1972 showed evidence of a world-wide increase in desire for lower power distance, but limited evidence of actual decrease. He concludes that since power-distance values are deeply ingrained, significant harmonization should not be expected in the near future. ${ }^{87}$

\section{Combined effect of greater collectivism and power distance in state- allocative economies}

Whether states in large power-distance cultures can successfully support material progress may to some extent be guided by the interaction between power distance and individualism. Hofstede notes that 'large power distance countries are ... likely to be more collectivist, and small power distance countries to be more individualist'. ${ }^{88}$

It has been noted above that when dealing with the state, economic actors in East Asian collectivist cultures tend to rely more on networks of personal relationships and negotiation than on legalism and written contracts. Such flexible relationships require a good deal of state discretion. It has also been noted above that collectivist cultures are more likely to have state-allocative legal systems. East Asian countries are generally relatively state-allocative, discretionary, collectivist, and medium power distance. It may be that these characteristics can only successfully support material progress when they are found together. The state-allocative model requires flexibility (discretion) and respect for authority (larger power distance). Collectivism may keep power distance to a medium level, and provide additional support for the use of discretion. This argument is nothing more than educated speculation, but it is worthy of further exploration.

In collectivist East Asia, many institutions appear to allow the private sector to have 'extensive pre-emptive involvement' in the lawmaking process 'that go beyond the well known phenomenon of lobbying in the West'. ${ }^{89}$ In Korea in particular, the business co-operation web 'extends far beyond families', and businesses regularly make use of close connections with government officials. ${ }^{90}$ The relationship between the state and individuals in Asia has been described as an 'informal', 'voluntary and non-authoritarian' process of negotiation and guidance. Decisions are made on the basis of 'a consensus of reciprocal expectations based on shared views of right and wrong' so that 'positive law is often superfluous', and the formal

87 id., pp. 42-3 and 46-7.

88 Although the 'Latin European countries, and in particular France and Belgium, combine medium power distances with strong individualism' (id., p. 55).

89 Pistor and Wellons, op. cit., n. 13, p. 281.

90 Gray, op. cit., n. 69, pp. 169 and 183-5. 
legal system is of 'marginal' importance. ${ }^{91}$ Furthermore, states in the region typically avoid 'legal conflicts in the implementation of rules' ${ }^{92}$ States which allow individuals such informal access can be described as 'permeable.'

Such permeability may act as a counterbalance to the interventionist (state-allocative) and discretionary role of the East Asian state. The East Asian state takes an invasive role in the private sector. In exchange, the state offers the private sector the opportunity to interact closely with the state. From the perspective of the economic actors, the use of personal contacts in state institutions may be seen as an extension of the use of personal business contracts in preference to anonymous contracting. That is, the private sector actively seeks to engage in close relationships with the state. In permeable states, economic actors may find predictability in their ability to affect the decision making processes of the state, rather than in limited state discretion. Discretion may be valued by the private sector, in particular when the private sector believes that it can influence the manner in which discretion is exercised. ${ }^{93}$ Some economic actors may be only too happy to take advantage of broad discretion, where they perceive that a benefit may result. For example, in Sri Lanka, customs officials reportedly blamed corruption on the private sector, whose employees fill out forms incorrectly and, when confronted with a choice between correcting the form or paying a bribe, choose the latter. ${ }^{94}$ As Jayasuriya has explained, in East Asia, vertical relationships with the state are of prime importance. It is only where horizontal relationships are important (as in the West) that there is a demand for economic calculability of the kind which can only be provided by a Weberian 'formal rational legal system' (that is, rule-based). ${ }^{95}$

In a notable effort to bring some sophistication to our understanding of the relationship between state discretion and economic development Hellman, Jones, and Kaufmann of the World Bank and the EBRD acknowledge that: ${ }^{96}$

91 B. Kamarul and R. Tomasic, 'The Rule of Law and Corporate Insolvency in Six Asian Legal Systems' in Law, Capitalism and Power in Asia, ed. K. Jayasuriya (1999) at 151.

92 Pistor and Wellons, op. cit., n. 13, p. 16. A separate study of six Asian countries, involving 115 interviews, found that bureaucrats often found that debt management under insolvency regimes could be more suitably resolved if they stepped outside of the formal legal framework: Kamarul and Tomasic, id., pp. 151-72.

93 K. Jayasuriya, 'Introduction: A Framework for Analysis' in Jayasuriya, op. cit., n. 91 , p. 10.

94 W. Tilakaratna, Issues of Transparency in Sri Lanka: A World Bank Study (1995) 7.

95 Jayasuriya, op. cit., n. 93, p. 10.

96 J. Hellman et al., 'Seize the State, Seize the Day': State Capture, Corruption and Influence in Transition' Policy Research Working Paper no. 2444 (2000) at 1. The paper analyses the findings of the 1999 Business Environment and Enterprise Performance Survey (data set at <www.worldbank.org/WBI/governance>) of firms in twenty-two transition economies, in combination with national economic performance indicators. 
our understanding of the main obstacles in the path of transition has generally been guided by an image of the state as a 'grabbing hand' discriminating against firms with low bargaining power to maximise the private interests of politicians and bureaucrats. Yet a recognition that powerful firms have been able to capture the state and collude with public officials to extract rents through manipulation of state power suggests that there are other dimensions of the relationship between the state and firms that could further enrich our understanding of the political constraints on the reform process.

The study identifies three types of state-private sector relationship. 'State capture' refers to the ability of the private sector to use 'illicit and nontransparent private payments to public officials' in order to shape the creation of laws. In this case, both the private sector and the public official gain from the relationship. 'Influence' also refers to the private sector's ability to shape laws. However, in contrast to state capture, this ability is based upon factors such as 'firm size, ownership ties to the state and repeated interactions with state officials', rather than private payments. In this case, it is the private sector which benefits from the relationship. Finally, 'administrative corruption' refers to the ability to 'distort the prescribed implementation of official rules' and policies, 'using private payments to public officials. In this case, it is public officials who benefit from the relationship. $^{97}$

The study draws three important conclusions for the purposes of this paper. First, 'influential and captor firms grow at substantially faster rates than other firms'. However, the former only benefit when they are operating 'in high capture economies, i.e. where state officials have created a sufficiently extensive private market for key under-provided public goods and other rent-generating advantages and thus share some portion of the rents associated with the state capture'. Second, 'the social costs of capture and influence for all other firms in the transition economies can be considerable'. ${ }^{98}$ Third, levels of state capture might be affected by levels of civil liberties - that is, 'the freedoms to develop views, institutions and personal autonomy apart from the state'. The study found an inverted Ushaped relationship (rather than a straightforward linear relationship) between civil liberties and state capture, suggesting that the 'partial introduction of civil liberties ... is associated with the emergence of state capture'. This is because 'the initial introduction of civil liberties (and other checks on abuse of power related to the supply of state capture) is insufficient to counterbalance the loss of control that has resulted from the dismantling of the controlling apparatus of the Communist Party'. However, 'once a threshold of basic civil liberties has been reached further reforms in this area are associated with much lower levels of state capture, as increasing civil society oversight raises the costs to politicians of state capture'. ${ }^{99}$ The

97 id., pp. 2 and 6.

98 id., pp. 3 and 4.

99 id., p. 31. 
implications for this paper are that whether or not permeable public-private relationships and broad state discretion are a good thing will depend upon the broader economic, political, and cultural context in which they arise. Analysis in this field appears to be moving into a new phase of improved subtlety and sophistication, and this is cause for hope. ${ }^{100}$

\section{A WAY FORWARD}

Hofstede's findings present a challenge to the underlying assumption of dominant legal reform policy, manifested in the promotion of a uniform market-allocative rule-based model for legal reform, that the perceptions and expectations of economic actors around the world do not vary significantly.

It seems that there may be a need for a multi-country study which questions members of the private sector about their perceptions of (a) the importance of legal systems and (b) the core components of an effective legal system. If these perceptions and expectations vary, then it is not clear that legal systems should be reformed towards the market-allocative rulebased model. Moreover, the long history of cultural divides 'should make us modest about expectations of fundamental changes in these value differences within our lifetime'. ${ }^{101}$ Even if reform towards the market-allocative rulebased model were found to be an advisable course of action, the strength and duration of cultural variation suggests that reform would necessarily involve a far more direct, radical, and politicized process than development organizations are able to contemplate in the current political and intellectual climate.

100 See, also, D. Kaufmann et al., 'Predicting Currency Fluctuations and Crises: Do Resident Firms Have an Informational Advantage?' Policy Research Working Paper no. 2259 (1999), which shows (at p. 15) that local managers predicted exchange rate volatility leading to the Asian financial crisis on the basis of 'private information' not 'captured by economic fundamentals', and thus not available to foreign experts (such as banks, currency forecasters, and rating agencies) who remained unaware of the impending doom.

101 Hofstede, op. cit., n. 2, pp. 135-6. 